\title{
ANALISANDO A ORGANIZAÇÃO DESCRITIVA DO GÊNERO CONSELHO EM CORREIO FEMININO, DE CLARICE LISPECTOR*
}

\author{
Leonardo Coelho Corrêa Rosado** \\ Mônica Santos de Souza Melo ${ }^{* * *}$
}

Resumo: O presente trabalho objetiva analisar a organização descritiva do gênero conselho em Correio Feminino, obra de Clarice Lispector, que reúne um conjunto de textos jornalísticos escritos especificamente para páginas/colunas femininas de jornais cariocas nas décadas de 1950 e 1960. A análise de nosso corpus levou em consideração o instrumental teórico-metodológico fornecido pela Teoria Semiolinguística do Discurso. Os resultados revelam que, no gênero conselho, há, predominantemente, a identificação do ser mulher-leitora bem como do ser mulher-modelo que funciona como ponto de referência para o primeiro. Esses seres, conforme o propósito temático do texto, podem ser qualificados como boas esposas, boas mães, boas donas de casa, e/ ou localizados em situacoenes sociais como a do casamento e a do trabalho.

Palavras-chave: Organização descritiva. Teoria Semiolinguística. Clarice Lispector.

\section{INTRODUÇÃO}

Em 2006, a Editora Rocco, sob a iniciativa da pesquisadora Aparecida Maria Nunes, publicou uma coletânea de textos jornalísticos de Clarice Lispector, intitulada Correio Feminino. Essa coletânea reúne textos inéditos que a escritora publicou em três páginas/colunas femininas nas décadas de 1950 e 1960: "Entre Mulheres", coluna do tabloide Comício, publicada entre maio e setembro de 1952; "Correio Feminino - Feira de Utilidades", produzida entre agosto de 1959 e fevereiro de 1961, para o jornal Correio da Manhã; e "Só para Mulheres", publicada entre abril de 1960 e março de 1961, para o jornal Diário da Noite.

\footnotetext{
* O presente trabalho é parte dos resultados encontrados para a pesquisa intitulada Imagens de Mulher em Correio Feminino de Clarice Lispector: uma abordagem semiolinguística, realizada entre agosto de $2007 \mathrm{e}$ julho de 2008, através do PIBIC/CNPQ/UFV, sob a orientação da professora Dr. ${ }^{a}$ Mônica Santos de Souza Melo.

** Mestrando em Letras/Estudos Discursivos, UFV; Bolsista CAPES/REUNI. Email: timtimcorre@hotmail.com

*** UFV; Professora Adjunta IV; Doutora em Estudos Linguísticos/Análise do Discurso, UFMG. Email: monicassmelo@yahoo.com.br
} 
A publicação desta coletânea possibilitou o conhecimento de uma outra Clarice diferente, em alguns sentidos, daquela apresentada em seus romances e contos. Além disso, esse material, por ser uma documentação de um momento sócio-histórico específico, possibilita a pesquisadores de outras áreas de conhecimento, como a Análise do Discurso (AD), um exame mais detalhado das representações, principalmente das mulheres (visto que se trata de textos publicados em páginas/colunas femininas), deste mesmo momento histórico.

Tomando essa coletânea como corpus de pesquisa, foi desenvolvido, através do $\mathrm{PIBIC} / \mathrm{CNPq} / \mathrm{UFV}$, o projeto de pesquisa Imagens de Mulher em Correio Feminino de Clarice Lispector: uma abordagem semiolinguística, que objetivava resgatar, por meio do instrumental teóricometodológico da AD Semiolinguística, as imagens de mulher vinculadas em alguns dos textos da coletânea.

O presente trabalho é, então, uma das etapas deste projeto e objetiva a analisar e configurar o modo de organização descritivo de um dos gêneros que compõem a coletânea: o gênero conselho. Nosso objetivo é, portanto, decompor, no modo em questão, os textos que se caracterizam como conselho dentro de Correio Feminino e apreender as descrições feitas principalmente em relação à mulher.

Para tal, o presente trabalho está organizado em três seções, além desta introdução e considerações finais: i) a descrição e o modo de organizạăão descritivo, que apresenta o conceito de modo de organização descritivo, bem como os componentes utilizados para realizar a construção descritiva, conforme os postulados da AD Semiolinguística; ii) o gênero situacional Conselho em Correio Feminino: algumas considerações sobre os niveis de restrições, que introduz alguns aspectos relevantes sobre a configuração deste gênero dentro do corpus em questão; e iii) a descrição em Correio Feminino: o gênero conselho e o modo de organização descritivo, que demonstra os resultados encontrados com relação à organização descritiva do gênero estudado. 


\section{A DESCRIÇÃO E O MODO DE ORGANIZAÇÃO DESCRITIVO}

Conforme postula a Teoria Semiolinguística do Discurso, o modo de organização descritivo é, assim como os modos de organização narrativo e argumentativo, um procedimento discursivo que se utiliza de algumas categorias de língua para produzir determinados efeitos, resultando, ao seu fim, em uma descrição.

Esse modo de organização se baseia em uma atividade de linguagem, o descrever, que consiste em fazer existir os seres nomeando-os, localizando-os e qualificando-os de maneira singular, através de um olhar sobre o mundo.

Entretanto, a atividade de descrever está estreitamente ligada ao contar, uma vez que as ações só têm sentido em relação às identidades e às qualificações dos actantes, bem como ao argumentar, visto que o descrever toma emprestado deste último certo número de operações lógicas para classificar os seres, e o argumentar só pode exercer-se a respeito dos seres que têm alguma identidade e qualificação.

O modo de organização descritivo ainda se compõe de três componentes, que são autônomos, porém indissociáveis um do outro: (i) nomear, (ii) localizar-situar e (iii) qualificar. Tais componentes são implementados no discurso por meio de procedimentos discursivos de identificação (nomear), de construção objetiva do mundo (localizar-situar e qualificar) e de construção subjetiva do mundo (qualificar), que, por sua vez, se utilizam de procedimentos linguísticos (categorias da língua) para a concretização da construção descritiva.

Além disso, a encenação descritiva, ordenada por um sujeito descritor, produz certo número de efeitos, que podem ser condicionados tanto por razões subjetivas, quanto pela finalidade da situação de comunicação em que a descrição se inscreve.

\subsection{Nomeação}

Para Charaudeau (1992), nomear é dar existência a um ser por meio de uma dupla operação que consiste na percepção de uma diferença no continum do universo e, concomitantemente, na classificação dessa 
diferença em uma semelhança. Tais operações, contudo, dependem estreitamente do sujeito que percebe, visto que o mundo não é um objeto pré-construído, que existe de maneira autônoma e exterior, mas que é construído por esse sujeito através de seu discurso (processo de transformação). Entretanto, tal sujeito não pode existir somente em razão de sua subjetividade, uma vez que ele faz parte de um determinado grupo social, que, de alguma maneira, sobredetermina, através de aspectos culturais, a sua visão de mundo. Logo, na sua mise en scène discursiva, o sujeito serve-se também do imaginário social de seu grupo para identificar, nomear, localizar e qualificar os seres.

Com relação aos procedimentos discursivos, a nomeação só é possível através dos procedimentos de identificação, que consistem em fazer existirem os seres, humanos ou não, nomeando-os. A identificação serve-se de diversas categorias linguísticas, tais como a denominação, a indeterminação, a atualização, entre outras, para nomear e identificar um determinado ser. Isso equivale a dizer que a identificação pode ser do tipo genérica (identificação genérica), na qual os indivíduos são nomeados por nomes comuns que os individualizam e os fazem pertencer a uma determinada classe de seres; ou do tipo específica (identificação específica), que, através de nomes próprios, identifica os seres naquilo que lhes é específico.

\subsection{Localização-Situação}

Localizar-situar é determinar para um ser o seu lugar no espaço e no tempo. Porém, ao mesmo tempo em que se localiza este ser no espaço e no tempo, também se atribui a ele algumas características, visto que, por efeito de retorno, a posição espaçotemporal dá a ele a sua razão de ser.

Discursivamente, a localização-situação se realiza através de procedimentos de construção objetiva, que, resumidamente, consistem em construir uma visão de verdade1 sobre o mundo, que qualifica os

\footnotetext{
${ }^{1}$ Charaudeau (1992, p. 674) aponta que essa visão de verdade não pode ser entendida como verdade do mundo, visto que se trata de um imaginário social compartilhado que representa e constrói o mundo segundo aquilo que o grupo social acredita ser a verdade. Para ele seria mais exato falar em verossimilhança realista do mundo.
} 
seres por meio de traços que podem ser verificados por qualquer outro sujeito além do sujeito falante. Assim sendo, a construção objetiva do mundo depende, para a construção de sua "objetividade", de: (i) uma organização sistematizada do mundo, que resulta de um ponto de vista científico sobre o mesmo; (ii) uma observação do mundo que é compartilhada pelos membros de uma comunidade social na forma de um consenso que se constitui para esses mesmos sujeitos como a realidade em si.

\subsection{Qualificação}

O componente qualificar está correlacionado ao componente nomear, entretanto, enquanto este estrutura o mundo em "constelação de seres", aquele atribui sentido particular aos seres, especificando-os a partir de um ponto de vista tanto objetivo quanto subjetivo.

É através deste ponto de vista subjetivo que o sujeito descritor satisfaz seu desejo de posse do mundo, uma vez que, ao qualificar um determinado ser, ele o singulariza e o especifica não somente por meio de sua racionalidade, mas também de seus sentidos e sentimentos.

Porém, pelo fato de este sujeito descritor viver em coletividade, as normas da prática social exercem coerções na qualificação dos seres em seu discurso. E isso possibilita-nos entender a qualificação como uma atividade discursiva em que o sujeito falante manifesta o seu imaginário individual e/ou coletivo em um jogo de conflito entre visões normativas (impostas pelas normas sociais) e visões subjetivas (condicionadas pela sua subjetividade). Desse modo, no plano discursivo, a qualificação se realiza através de procedimentos de construção objetiva e construção subjetiva do mundo.

\section{O GÊNERO SITUACIONAL CONSELHO EM CORREIO FEMININO: ALGUMAS CONSIDERAÇÕES SOBRE OS NÍVEIS DE RESTRIÇÕES}

Como apontado em nossa introdução, o presente trabalho é o resultado de uma pesquisa intitulada Imagens de mulher em Correio Feminino de Clarice Lispector: uma abordagem semiolinguística, que objetiva 
resgatar, por meio do instrumental teórico-metodológico da AD Semiolinguística, a representação feminina cristalizada em alguns textos dessa coletânea.

Para tal, precisamos, em um primeiro momento, apreender os gêneros situacionais que a compunham e, então, selecionar quais gêneros trabalhar. Optamos, durante a pesquisa, por trabalhar com os gêneros mais e menos recorrentes. Conforme a tabela 1 abaixo, os gêneros mais e menos recorrentes são, respectivamente, os gêneros conselho e teste.

Tabela 1 - Gêneros situacionais encontrados em Correio Feminino

\begin{tabular}{|c|c|c|c|c|c|}
\hline \multirow[b]{2}{*}{$\begin{array}{l}\text { Gêneros } \\
\text { Encontrados }\end{array}$} & \multicolumn{5}{|l|}{ Jornais } \\
\hline & $\begin{array}{l}\text { Comício } \\
\text { "Entre } \\
\text { Mulheres" }\end{array}$ & $\begin{array}{l}\text { Correio da Manhã } \\
\text { "Correio } \\
\text { Feminino" }\end{array}$ & $\begin{array}{l}\text { Diário da } \\
\text { Noite } \\
\text { "Só para } \\
\text { Mulheres" }\end{array}$ & Mais & Total \\
\hline Conselho & 2 & 25 & 18 & - & 45 \\
\hline Comentário & - & 24 & 13 & - & 37 \\
\hline Conto & 4 & - & - & 2 & 6 \\
\hline Crônica & 3 & 1 & - & 1 & 4 \\
\hline Dica & 0 & 15 & 16 & - & 31 \\
\hline Gênero Híbrido & 4 & 17 & 19 & - & 40 \\
\hline Reflexão & - & 7 & 4 & - & 11 \\
\hline Teste & - & 1 & 2 & - & 3 \\
\hline Total & 13 & 90 & 72 & 3 & 178 \\
\hline
\end{tabular}

Dos 178 textos que compõem a coletânea, 45 textos correspondem ao gênero conselho, e 3 textos correspondem ao gênero teste. Além disso, percebemos que os textos considerados como representantes do gênero situacional conselho foram publicados nas três páginas/colunas de Clarice Lispector ("Entre Mulheres", "Correio Feminino - Feira de Utilidades" e "Só para Mulheres"). 
Neste trabalho, o nosso foco é o gênero conselho, porém, como se configura este gênero no corpus em questão? ${ }^{2}$

Seguindo os procedimentos teórico-metodológicos fornecidos pela Semiolinguística para a análise e configuração de gêneros ${ }^{3}$, temos, em relação aos níveis de restrições do gênero situacional conselho, no corpus em questão, a seguinte configuração:

a) Aspectos situacionais: o gênero conselho é um gênero cujo domínio de comunicação é o domínio midiático, visto que, em um primeiro instante, tal gênero fora publicado nas páginas/colunas femininas de Clarice Lispector. Tal domínio institui uma situação de comunicação de entretenimento (contrato de entretenimento), na qual o $E^{4} c^{4}$, através de seu EUe (1), desdobra-se em um EUe (2), para com isso mascarar ou a identidade do sujeito comunicante ou a do sujeito enunciador. Além disso, tal desdobramento funciona como uma estratégia discursiva de captação e de credibilidade do discurso ${ }^{5}$. Ocorre também que esse EUe (1), através do EUe (2), se dirige a um TUi, formado basicamente de mulheres, com uma finalidade, aconselhar (ou seja, propor ao TUd uma ação futura que o beneficiará e o retirará de uma situação atual desfavorável) este último a assumir ou não assumir algum modelo de mulher estabelecido em seu discurso, em relação a diversos propósitos: i) beleza, ii) moda, iii) casamento e família, iv)

\footnotetext{
${ }^{2}$ Mais informações sobre a configuração do gênero conselho em Correio Feminino podem ser obtidas através da leitura do artigo de Corrêa-Rosado e Melo: Conselhos de minha Clarice: uma análise semiolinguística do gênero situacional conselho em Correio Feminino de Clarice Lispector (no prelo).

3 A Teoria Semiolinguística entende que o gênero discursivo é o resultado da interseção de três níveis de restrições: i) das restrições situacionais; ii) das restrições discursivas; e iii) das restrições formais. Cada um desses níveis possui várias outras subcategorias para a configuração. Assim, as restrições situacionais são caracterizadas pela finalidade, propósito, identidade e circunstâncias materiais; as restrições discursivas pelos modos enoncivos, modos enunciativos, modos de tematização e modos de semiologização; e as restrições formais pela mise en scène textual, pela construção textual interna, pela fraseologia e pela construção gramatical. Porém, pelo fato de as restrições situacionais condicionarem as restrições formais, via restrições discursivas, o gênero do discurso, no âmbito da Semiolinguística, é denominado gênero situacional (CHARAUDEAU, 2004).

${ }^{4}$ As siglas, EUc, EUe, TUd, TUi, correspondem, no âmbito da AD Semiolinguística, aos seguintes sujeitos: suj

eito comunicante (EUc), sujeito enunciador (EUe), sujeito destinatário (TUd) e sujeito interpretante (TUi).

${ }^{5}$ Para mais informações consultar o artigo publicado na Revista Vertentes (número 32): Organizaçãa enunciativa em Correio Feminino: um estudo do gênero teste sob o olhar da teoria semiolinguistica, de autoria de Corrêa-Rosado e Melo (2008).
} 
problemas diários, v) educação dos filhos, entre outros. Para isso, o sujeito enunciador (1) seleciona duas visadas: i) visada de incitação (fazer fazer) e ii) visada de informação (fazer saber), podendo, quando o propósito o permite, selecionar outras visadas, tais como a visada de instrução (fazer saber-fazer) e a de demonstração;

b) Aspectos discursivos: as restrições situacionais é que condicionam as restrições formais, via restrições discursivas. Essas últimas, no gênero em questão (conselho), mostram que este, em relação aos modos enoncivos (ou modos de organização do discurso), se caracteriza, predominantemente, pela utilização do argumentativo e do descritivo. Já em relação aos modos enunciativos, ou seja, aos comportamentos alocutivo, elocutivo e delocutivo, o gênero conselho faz uso dos comportamentos alocutivo e delocutivo, podendo, em alguns casos, utilizar-se do elocutivo (principalmente quando o EUe (1) assim o desejar). Os modos de tematização revelam que no conselho os propósitos maiores (beleza, por exemplo) são divididos em vários subtemas, segundo a finalidade do texto;

c) Aspectos formais: o gênero situacional conselho se configura em termos de mise en scène textual por meio de um paratexto que dispõe um título (este com função de resumir o conteúdo do texto, estabelecendo, com isso, uma ligação catafórica com ele) e um texto ou corpo textual abaixo do título. Em relação à composição textual interna, os textos do gênero conselho não apresentam nenhuma seção delimitada, porém é possível encontrar momentos diferentes no texto: i) o momento introdutório (organizado discursivamente pelo comportamento delocutivo) evidencia, de forma genérica, qual é a situação desfavorável em que EUe (1) não quer que o TUd esteja; e ii) momento de aconselhamento (organizado discursivamente pelo comportamento alocutivo), momento em que de fato o EUe (1) aconselha o TUd sobre algum propósito. A fraseologia do gênero Conselho emprega algumas expressões, tais como "minhas amigas" "minhas leitoras", "minhas caras", "minha amiga", aproximando locutor e interlocutor nesta situação de comunicação. Já a construção gramatical deste gênero mostra que o EUe (1) utiliza, predominantemente, dois tipos de construção para concretizar sua finalidade: (i) construção com frases em modo imperativo e (ii) construção com frases com verbos modais, tais como os verbos dever e ter; bem como faz uso da pronominalização do "você" e correspondentes. 


\section{A DESCRIÇÃO EM CORREIO FEMININO: O GÊNERO CONSELHO E O MODO DE ORGANIZAÇÃO DESCRITIVO}

Conforme apontado na seção 2, a organização descritiva de um texto ou de um gênero do discurso se constrói a partir dos componentes nomear, localizar-situar e qualificar. Para apresentarmos os resultados obtidos para esse modo de organização, levaremos em conta esses mesmos componentes, bem como a configuração do gênero apresentada na seção 3 .

\subsection{Nomeação}

A encenação descritiva do gênero Conselho, no corpus em estudo, está diretamente ligada aos componentes de sua organização enunciativa. Assim, devido ao comportamento alocutivo da organização enunciativa, comportamento este no qual o locutor implica o interlocutor em algum fazer, o EUe do gênero conselho identifica, na construção descritiva, o ser ao qual ele se dirige: a mulher-leitora. Essa mulher-leitora não é frequentemente identificada de forma direta; na verdade, percebemos a sua presença no discurso através de marcas que caracterizam o comportamento alocutivo (pronomes de tratamento "você" e correspondentes; desinência número-pessoal do modo imperativo dos verbos).

Além do mais, essa identificação da mulher-leitora pode ser percebida pelas formas linguísticas que mantêm uma relação de contrariedade semântica ${ }^{6}$ entre si no âmbito do texto:

\footnotetext{
${ }^{6}$ Segundo Charaudeau (1992), as relações de contrariedade semântica são aquelas em que uma palavra não pode ser colocada no lugar de outra sem pena de mudar radicalmente o sentido de um enunciado. Dentre os tipos de relações de contrariedade, Charaudeau menciona: (i) a de oposição binária: dois vocábulos estão em oposição binária quando eles têm necessidade um do outro para se constituírem semanticamente; (ii) a de oposição serial: dois vocábulos estão em oposição serial quando eles se inscrevem em uma série de vários vocábulos que têm por propriedade comum serem semanticamente incluídos em um vocábulo mais genérico; (ii) a de oposição simétrica: dois vocábulos estão em oposição simétrica desde que eles impliquem reciprocamente e simultaneamente um ao outro; (iv) a de oposição assimétrica: dois vocábulos estão em oposição assimétrica quando um pressupõe a existência do outro, porém de forma não recíproca.
} 
(1) Os homens costumam fugir apavorados deste tipo de mulher. (relação de oposição binária) (CONS16)

(2) Mas escolham seu marido como companheiro de sua vida, o homem que hão de amar e respeitar até o fim de seus dias. (relação de oposição simétrica) (CONS10)

Há ainda alguns casos em que o EUe utiliza os procedimentos linguísticos de denominação genérica para identificar esta mulher-leitora:

(3) Pois, minhas amigas, o que acontece é que elas esqueceram a sua condição de mulher. (denominação genérica com o substantivo "amiga") (CONS19)

A identificação desta mulher-leitora está também relacionada ao propósito temático do texto. Assim, se o propósito do texto é o casamento, a mulher-leitora pode ser identificada como esposa; se o propósito for referente à educação dos filhos, a mulher-leitora pode ser identificada como mãe. O conselho Ser Mãe... (publicado no Correio da Manhã, em 9 de setembro de 1959), é, por exemplo, um dos textos em que a mulher-leitora é identificada como mulher-mãe. Vejamos um fragmento do texto:

(4) Minha amiga, a primeira qualidade para uma mulher ser Mulher é saber ser Mãe. Não se descuide desse dever. Não seja o monstro responsável pelas futuras falhas do seu filho, deixando-o levianamente crescer longe de seus olhos e de seus carinhos. (CONS 6)

Temos também outros exemplos que evidenciam a relação do propósito temático com a identificação do ser mulher-leitora:

(5) Cuidado, portanto, na maneira como trata seu marido, minha amiga leitora! Pense no que será perdê-lo... e faça-lhe as vontades. 
Quando não, use de diplomacia e delicadeza. Garanto que é o melhor meio de domá-los (mulher-esposa) (CONS5)

(6) Primeiramente, deve mostrar-lhe por diversos meios que tem confiança nele: ao mesmo tempo deve tomar interesse por seu trabalho, ouvir suas longas dissertações sobre os acontecimentos do dia, e procurar manter sempre a casa limpa, apresentar refeições gostosas e agradáveis à vista. (mulher-dona-de-casa e mulheresposa) (CONS45)

(7) Em segundo lugar, sua voz deve sair naturalmente, rica em entonações discretas, apenas, e não exageradas. (mulher-mulher ${ }^{7}$ ) (CONS30)

Há também as identificações ligadas não ao status social, mas à faixa etária das mulheres. Este tipo de identificação, conforme o exemplo 9, sempre representa uma mulher mais velha, entre 25 e 40 anos $^{8}$ :

(8) Portanto, amiga leitora, se a sua certidão está lhe mostrando que os vinte anos já vão se distanciando, não se atormente, não se preocupe, não lute desesperada e inutilmente pra recuperálos. Seja você mesma, sedutora, elegante, bonita, com a idade que possui. (mulher-adulta) (CONS15)

Portanto, pelos exemplos, concluímos que a identificação da mulher-leitora pode se dar tanto pelo status social: mulher-mãe, mulhertrabalhadora, mulher-dona-de-casa, mulher-esposa/noiva/namorada e mulhermulher, quanto pela faixa etária do público: mulher-adulta.

\footnotetext{
${ }^{7}$ Quando utilizamos a expressão mulher-mulher para remeter à identificação da mulher-leitora estamos utilizando-a em contraste com as outras, mulher-esposa e mulher-mãe, dos outros conselhos. Essa expressão, dentro desse contexto de identificação, é somente uma forma geral de tratar a mulherleitora identificada, pois há alguns conselhos em que ela não é categorizada em nenhum status social específico. Não fazemos, desta forma, nenhum tipo de julgamento que leve em conta os aspectos e as condições sociais do gênero feminino.

${ }^{8}$ Segundo Buitoni (1981), no contexto do final da década de 1950 e início da década de 1960, as mulheres eram consideradas jovens entre a faixa dos 18 e 25 anos e adolescentes entre a faixa de 14 e 18 anos. Isso explica porque o EUe (1), no exemplo 9, utiliza a expressão "seus vinte anos já vão se distanciando".
} 
A relação dos componentes da construção descritiva e da construção enunciativa também se evidencia quando o EUe apresenta o modelo de mulher que ele deseja que o TUd adote. Geralmente isso ocorre no "momento de introdução" do gênero, momento este enunciado de forma delocutiva. Desta forma, o comportamento delocutivo da organização enunciativa, pelo fato de não implicar nem o interlocutor nem o locutor - o discurso fala sozinho -, dá a este modelo encenado um estatuto de verdade geral, compartilhada pelos indivíduos de um determinado grupo social. E este modelo que o EUe deseja que suas leitoras adotem (ou não adotem, se se trata de um antimodelo) em relação à beleza, à saúde, ao comportamento, ao casamento, aos problemas cotidianos, à moda. Assim, o EUe também identifica e nomeia um ser-modelo que se torna o ponto de referência para o TUd avaliar se ele se encontra em uma situação desfavorável.

Este ser-modelo é identificado como uma mulher, que, dependendo do propósito particular de cada texto, pode assumir diversos status sociais: i) mulher-trabalhadora(1); ii) mulher-mãe(1); iii) mulheresposa/noiva/namorada(1); e iv) mulher-mulher(1)'. As identificações desta mulher-modelo, enunciadas de forma delocutiva, assemelham-se, portanto, às identificações da mulher-leitora, enunciadas de forma alocutiva.

Os procedimentos linguísticos que identificam esta mulhermodelo são os de denominação genérica, como podemos observar nos exemplos que se seguem:

(9) Existem muitas e muitas também são as mulheres que as cultivam, sem pensar que com isso estão se prejudicando. (denominação genérica com o substantivo "mulher") (CONS16)

(10) Ser mãe... não é apenas dar a luz uma criança. (denominação genérica com o substantivo "mãe") (CONS6)

9 Utilizamos o símbolo “(1)” à frente dos termos para distinguir esses daqueles usados na identificação da mulher-leitora.

ROSADO; MELO - Analisando a organização descritiva... 
Pelos exemplos 9 e 10 acima, percebemos que, geralmente, essa identificação da mulher-modelo vem atualizada pelos artigos definidos "a" ou "as". Conforme aponta Charaudeau (1992), os artigos definidos podem apresentar, em sua especificidade, um valor de generalidade, que consiste em considerar o ser atualizado pelo artigo como o representante de um conjunto de seres que possuem as mesmas características. Assim, quando na construção descritiva do gênero conselho o ser mulhermodelo aparece atualizado por este artigo, isso indica que esta mulher representa todas as mulheres que se encontram nesta situação.

A identificação desta mulher-modelo também é possível pelas relações de contrariedade semântica:

(11) Uma mulher que recebe o chefe do lar com um ar cansado, e desfiando a ele um rosário de lamúrias sobre seus problemas caseiros, brigas com as empregadas e as malcriações dos filhos, está entediando o marido e só conseguirá que ele se aborreça gradativamente do seu lar. (relação de oposição simétrica) (CONS45)

Há, no entanto, alguns casos em que a mulher-modelo é denominada por um nome próprio (denominação específica), porém esse tipo de denominação só ocorre em situações bem específicas:

(12) Não vou afirmar que qualquer uma poderá ter um rostinho de Elizabeth Taylor ou o corpo de uma Gina Lollobrigida, mas um bonito sorriso, uma pele macia, uns cabelos sedosos, uns olhos brilhantes, isso todas nós podemos obter. (denominação especifica) (CONS8)

Muitas vezes à identificação da mulher-modelo se acrescenta a identificação de outros seres, como o ser marido ou homem (1) e o ser filho/filha ou criança (1), que se relacionam com o modelo proposto pelo EUe. Isso ocorre porque geralmente a descrição faz bastante uso das relações de oposição (eixo paradigmático) da língua. Vejamos alguns exemplos de identificação desses outros seres: 
(13) As meninas que já são mocinhas precisam muito de conselhos de beleza pra se sentirem amparadas; não sabem muito bem o que são, não sabem propriamente o que querem ser. E ainda por cima, desconfiam da vontade de "mandar" dos outros. (CONS25)

(14) Sem consciência disso, ela continua o seu "show", alheia ao constrangimento do companheiro e risinho maldoso dos estranhos... Os homens costumam fugir apavorados deste tipo de mulher. (CONS16)

Portanto, o ser mulher-modelo pode manter relações diversas com outros seres discursivos para assim concretizar a construção descritiva do EUe dentro da situação de comunicação midiática conselho, no corpus em questão.

\subsection{Localização/Situação}

Como o componente nomear do gênero conselho identifica, em princípio, a mulher-leitora, que pode assumir diversos status sociais dependendo do propósito do texto, e uma mulher-modelo, que serve de referência a esta mulher-leitora, o componente localizar/situar irá determinar os ambientes físicos e as situações sociais em que estes seres poderão estar.

No gênero conselho, os ambientes sociais e físicos são praticamente inexistentes, pois estes cedem lugar às situações sociais, como jantares, trabalho, casamento. $\mathrm{Na}$ verdade, o único ambiente físico que aparece é o ambiente "casa", e mesmo assim em casos bem restritos. É o caso do exemplo 6 acima, em que notamos a presença do ambiente físico "casa", qualificado como "limpa". Nesse mesmo texto, o ambiente social "lar" também aparece e ele se mostra composto de vários elementos: marido, esposa, casa, filhos.

Enquanto o ambiente social "lar" não é muito contemplado pelo EUe deste gênero, as situações sociais, ao contrário, já são mais descritas. No texto Perfume e veneno, publicado pelo Diário da Noite em 11 de junho de 1960, as situações sociais "almoço" e "jantar" são encenadas como 
situações sociais nas quais a mulher deve assumir algumas atitudes em relação ao perfume que usa. O EUe mostra que o uso de perfumes deve considerar sempre a situação social:

(15) Talvez seu tipo combine com um perfume penetrante, envolvente. É, mas não dá certo usá-lo para um almoço ou jantar. Você "envenenará" a comida, e tirará a fome das pessoas ao seu lado. (CONS24)

Tal referência a situações sociais como "almoço" e "jantar", ou seja, situações de convívio e entretenimento, ocorre quando o propósito do texto assim o requerer. Em outras palavras, nem todos os textos do gênero conselho necessitam localizar/situar a mulher em situações ou ambientes sociais, pois a temática predominante deste gênero é a da beleza (12 textos $-26,67 \%$ ), seguida da temática feminilidade (8 textos $17,78 \%)$.

Outra situação social construída neste gênero é a situação de trabalho, que é citada em dois textos: Para as que trabalham fora... (Correio da Manhã, 20 de março de 1960) e $O$ dever da faceirice (Correio da manhã, 23 de dezembro de 1959). No caso do primeiro texto, a situação social de trabalho recebe uma qualificação por parte do EUe (1) que o associa a aspectos masculinos, isto é, o trabalho é visto, por este EUe, como uma atividade exercida pelo homem, uma atividade que quando é exercida pela mulher pode masculinizá-la:

(16) Se você trabalha fora, comanda ou dirige equipes, trata de assuntos comerciais com homens, interessa-se, por força da profissão, pela cotação do mercado, pela contabilidade mecanizada, enfim, se você é obrigada a deixar de lado as maneiras delicadas e muito femininas, muito cuidado. $\mathrm{O}$ grande perigo que a ameaça é a masculinização de seus gestos, de sua palestra, de seus pensamentos. (CONS19)

Quando o propósito o permite, a situação social de casamento é também construída pelo EUe do gênero conselho. No texto Compreenda 
seu marido, publicado no Correio da Manbã em 4 de setembro de 1959, percebemos a existência desta situação social. Ela é caracterizada neste texto, bem como nos outros textos que também a evidenciam (CONS10 e CONS45), como uma situação na qual a mulher-esposa deve exercer uma série de práticas em relação ao marido para assim conseguir manter a estabilidade do casamento e, por conseguinte, encontrar a felicidade, pois o texto argumenta que a situação de casamento é responsável pela felicidade da mulher, ou seja, a mulher só é feliz quando está casada.

Além do mais, as práticas que caracterizam esta situação social estão sempre relacionadas com a submissão da mulher ao marido, pois este é o chefe do lar e dono da casa:

(17) Uma mulher que recebe o chefe do lar com um ar cansado, e desfiando a ele um rosário de lamúrias sobre seus problemas caseiros, brigas com as empregadas e as malcriações dos filhos, está entediando o marido e só conseguirá que ele se aborreça gradativamente do seu lar. Numa tal atmosfera, os aborrecimentos que o marido talvez traga da rua, suas preocupações, seus problemas, não encontram uma válvula de escape e aumentam, tornando-o mal humorado, nervoso e pouco apto para resolver as situações que o aguardam no dia seguinte. (CONS 45)

\subsection{Qualificação}

Como já apontamos, as temáticas de beleza e feminilidade neste gênero são as que predominam (juntas elas correspondem ao total de 20 textos - 44, 45\%). Logo, a qualificação dos seres identificados está praticamente relacionada a estas temáticas, embora as outras também permitam suas qualificações.

Além do mais, temos que levar em conta o fato de que o componente nomear identifica dois seres principais, a mulher-leitora e a mulher-modelo. Como o último serve de referência para o primeiro, uma vez que ele se configura como um modelo a ser seguido, o componente qualificar ocorre não no aspecto do ser, mas no aspecto do deve ser, pois o ponto de vista que predomina não é o da mulher-modelo (ela é somente 
um modelo), mas o da mulher-leitora: é este ser que irá realizar uma ação futura em seu próprio benefício.

Nesse sentido, percebemos que, no gênero conselho, a mulhermodelo, em seu status social de mulher-mulher, é qualificada como uma mulher que é bela ou que sempre procura estar bela e elegante. Mesmo nos casos em que a beleza não é um privilégio dado pela natureza, há soluções propostas pelo EUe: a mulher pode recorrer a cirurgias plásticas e a diferentes tipos de cosméticos que "melhoram o que a natureza deu à mulher". Logo, a beleza é contemplada pelo EUe do gênero conselho como uma propriedade que qualifica a mulher. Assim, dizer que a mulher-modelo é bela presume que a mulher-leitora deva também o ser, ou procurar meios para que seja.

A qualificação e definição da propriedade beleza faz-se presente nos textos que lidam com essa temática (CONS4, CONS14, CONS15, CONS17, CONS26, CONS28, CONS31, CONS36, CONS41, CONS42, CONS44). Vejamos alguns exemplos:

(18) Há muitos conselhos para aumentar a beleza. Uns dizem respeito à pele seca, outros aos cuidados com o cabelo, mas nenhum fala, ou pelo menos poucos falam das grandes vantagens de uma atitude otimista para com a vida. O otimismo, a alegria, o riso franco são os melhores auxiliares de beleza sem sombra de dúvida. (CONS26)

(19) A beleza não tem idade. A mulher inteligente sabe disso. (CONS15)

(20) Não existem mulheres feias. Não é uma afirmação leviana, digo-a baseada na experiência, que adquiri sobre à arte de embelezar a mulher e atrair a atenção masculina. Com a variedade de cosméticos e artificialismo que os laboratórios atualmente criam para melhorar o que a natureza deu à mulher, só é feia quem quer. (CONS8)

A partir desses exemplos, percebemos que a beleza é descrita como o resultado não somente da utilização de cosméticos, mas também de uma atitude positiva para com a vida. Contudo, o cuidado interior aparece como um hábito que deve ser cultivado para, assim, manter a 
juventude no brilho olhos e nos traços da face, pois as atitudes positivas em relação à vida são, segundo o EUe, as causadoras da juventude. Logo, a aparência exterior, que, numa primeira leitura, parece não ser descrita, surge como o foco da descrição: cultiva-se a beleza interior para realçar a beleza exterior.

Assim, no gênero conselho a propriedade da beleza é um aspecto fundamental na qualificação da mulher-modelo e, por conseguinte, da mulher-leitora. A mulher deve manter-se bela e elegante para atingir um determinado objetivo. Mas que objetivo seria este?

Nos textos que lidam com a temática da beleza, bem como em outros textos deste gênero, a beleza da mulher também é descrita como um meio de ser atraente, em outras palavras, a beleza é um atributo que a mulher cultiva para, com isso, atrair a atenção e os olhares masculinos. Como já apontamos anteriormente, conjuntamente à identificação da mulher-modelo, há, em alguns textos, a identificação do ser homem que pode assumir diversos status sociais, dependendo da temática do texto. Nos textos que tocam a temática da beleza, o homem aparece como o espelho que reflete a imagem da mulher bela, pois é para eles que a mulher se "produz" e cuida de si própria:

(21) A mulher moderna sabe que, apesar da evolução das ciências e das artes, o homem continua o mesmo, e o principal atrativo que encontra na mulher é a sua aparência física. Julgar que porque se casou com ele está dispensada de seduzi-lo é outro grave erro. O homem é volúvel. Sua busca da "mulher ideal" é apenas a forma romântica com que encobre essa volubilidade, $\mathrm{e}$ geralmente envelhecem sem descobrir realmente o que querem da mulher. Só sabem que a querem. Sempre bonita e renovada, se possível. (CONS13)

No exemplo 21, percebemos que a mulher-modelo sabe que o homem necessita ser sempre conquistado. Isso implica que esta mulher sempre procura meios de seduzi-lo, de atrair-lhe a atenção e também admiração, pois é este homem que mulher objetiva "agarrar". O homem, por seu turno, quer que a mulher esteja sempre bela e renovada para, com isso, concretizar seus objetivos, sejam eles sexuais ou afetivos. 
Desta forma, considerando a finalidade do gênero, o componente qualificar constrói uma qualificação da mulher-leitora como aquela que deve cultivar o modelo de beleza e elegância, para atrair a atenção e admiração dos homens. A beleza e a elegância, neste sentido, são símbolos de sedução e atração masculina.

Outra propriedade que a mulher-leitora deve cultivar é aquela denominada feminilidade. A feminilidade é compreendida como a qualidade que faz de uma mulher uma mulher, ou seja, a feminilidade está associada à representação feminina que os indivíduos sociais deste contexto histórico fazem.

A elegância geralmente está associada a esta temática, pois a mulher que é elegante revela sua feminilidade na maneira de se vestir e de se comportar. Outro aspecto ligado à feminilidade é a inteligência, inteligência esta que deve ser usada para manter a beleza (exemplo 22), bem como para reforçar outras propriedades:

(22) A mulher esclarecida sabe disso. Ela estuda, ela lê, ela é moderna e interessante sem perder seus atributos de mulher, de esposa e mãe. (CONS3)

Neste exemplo, o esclarecimento da mulher não aparece desvinculado de outros atributos da feminilidade, como ser boa mãe e ser boa esposa; de fato, este esclarecimento proporciona à mulher conhecer mais suas condições e papéis sociais para assim utilizá-los com mais propriedade. Percebemos, com isso, que o esclarecimento da mulher é descrito como uma qualidade que não faz a mulher se libertar das normas e regras sociais, mas a torna ainda mais responsável por seus "deveres".

O saber ser mãe também caracteriza a feminilidade, como vimos no exemplo 5 acima. Esta é, na verdade, a propriedade que mais caracteriza a feminilidade, pois "a primeira qualidade para uma mulher ser Mulher é saber ser Mãe”. A mulher-modelo apresenta esta propriedade: ela também é mãe.

Nos textos de propósito sobre educação dos filhos (CONS7, CONS25, CONS32 e CONS 39), notamos que a qualidade de ser mãe é 
descrita pelo EUe como associada ao amor. É a partir do amor que a mãe nutre pelo filho que ela pode educá-lo, e ao educá-lo pelo amor, ela se qualifica como uma boa mãe:

(23) Uma verdadeira mulher e mãe sabe que seus deveres vão além de alimentar, enfeitar e agasalhar o seu filho. Antes de tudo, deve dar-lhe amor. Amor que é devoção, cuidado, orientação e, sobretudo, participação em seus problemas e dificuldades. (CONS6)

No exemplo 23 acima, observamos que os substantivos "mulher" e "mãe" estão em uma relação de equivalência semântica entre si, o que nos leva a entender que ser mulher é o mesmo que ser mãe e vice-versa. Além disso, esses dois nomes aparecem qualificados pelo adjetivo 'verdadeiro', reforçando ainda mais a relação entre os dois nomes. Tais marcas linguísticas evidenciam que a mulher-modelo é mulher por ser uma verdadeira mãe.

No gênero conselho, a feminilidade também está associada ao ser uma boa esposa (exemplo 22). Este atributo é descrito nos textos que lidam com o propósito do casamento. Nestes textos, além da qualificação da mulher, há também a qualificação do homem, que sempre é representado de forma genérica e imutável. Nesse sentido, os procedimentos linguísticos que definem esta qualidade da mulher estão em relação de oposição binária com os procedimentos linguísticos que qualificam o esposo. Isso equivale a dizer que, no casamento, enquanto o homem permanece imutável, ou seja, suas propriedades são as mesmas ("o homem continua o mesmo"), a mulher, ao contrário, precisa se adaptar às exigências deste homem, se deseja tê-lo ao seu lado, para assim ser considerada uma boa esposa.

Como apontamos para o componente localizar/situar, o casamento, encenado neste gênero como uma situação social que envolve, além da mulher, o homem, exige certos comportamentos e práticas da mulher. Geralmente, percebemos que essas práticas, mesmos nos casos em que são realizadas em prol do lar, são sempre de submissão aos desejos e vontades dos homens. Assim, é por meio dessas práticas que a mulher adquire sua qualidade de boa esposa, e, desta forma, reforça a sua feminilidade. 
Portanto, o componente qualificar do gênero conselho, no corpus em estudo, encena, através da mulher-modelo, diversas propriedades que a mulher-leitora deve assumir. A beleza e a elegância, a feminilidade, o ser mãe e o ser esposa são estas propriedades construídas pelo EUe (1), através de seu EUe (2), que representam as qualidades da mulher no contexto histórico em que os textos das colunas femininas de Clarice Lispector aparecem.

\section{CONSIDERAÇÕES FINAIS}

Esse trabalho mostrou, em linhas bem gerais, o desenvolvimento de uma pesquisa que procura apreender a representação feminina na coletânea Correio Feminino, de Clarice Lispector, a partir dos pressupostos teórico-metodológicos fornecidos pela AD Semiolinguística.

Os resultados encontrados quanto à organização descritiva do gênero conselho mostram que, neste gênero, há, em primeiro plano, a identificação da mulher-leitora que, dependendo do propósito temático do texto, pode assumir variados status sociais, como o de mulher-esposa, por exemplo. Além disso, há também a identificação de um ser mulhermodelo que funciona como ponto de referência para essa mulher-leitora. Esses dois principais seres podem estar localizados em situações sociais como a do casamento, do trabalho, de jantares, entre outras, bem como serem qualificados como belos e femininos, ou seja, como seres que possuem o atributo de boa esposa, boa mãe e boa dona-de-casa.

\section{REFERÊNCIAS}

BUITONI, D. H. S. Mulher de papel: a representação da mulher na imprensa feminina brasileira. São Paulo: Edições Loyola, 1981.

CHARAUDEAU, P. Langage et discours - éléments de sémiolinguistique (théorie et pratique). Paris: Hachette, 1983.

Grammaire du sens et de l'expression. Paris: Hachette, 1992.

. Visadas discursivas, gêneros situacionais e construção textual. In: MACHADO, I. L.; MELLO, R. (Orgs.). Gêneros: reflexões em análise do discurso. Belo Horizonte: NAD/FALE/UFMG, 2004. p. 13-41.

LISPECTOR, C. Correio Feminino. Rio de Janeiro: Rocco, 2006. 
Recebido em 28/09/10. Aprovado em: 22/04/11.

Title: Analyzing the descriptive organization of the genre advice in Correio Feminino, by Clarice Lispector

Authors: Leonardo Coelho Corrêa Rosado; Mônica Santos de Souza Melo

Abstract: The present work analyzes the descriptive organization of the genre advice in Correio Feminino, by Clarice Lispector, which assembles a set of journalistic texts written specifically for the feminine pages / columns of newspapers from Rio de Janeiro during the 1950s and 1960s. The analysis of the selected corpus employed the theories and methods of Semiolinguistics of Discourse. The results revealed that in the genre advice there is, mainly, the identification of what is a woman-reader, as well as the model-woman, which functions as a point of reference for the former. Such beings, according to the thematic goal of the text, can be qualified as good wives, good mothers, or good housewives and/ or can be situated in social situations as that of marriage and of work.

Keywords: Descriptive organization. Semiolinguistics. Clarice Lispector.

Titulo: Analizando la organización descriptiva del género consejo en Correo Femenino de Clarice Lispector

Autores: Leonardo Coelho Corrêa Rosado; Mônica Santos de Souza Melo

Resumen: El presente trabajo objetiva analizar la organización descriptiva del género consejo en Correo Femenino, obra de Clarice Lispector, que reune un conjunto de textos periodísticos escritos especificamente para páginas/columnas femeninas de periódicos cariocas en las décadas de 1950 y 1960. El análisis de nuestro corpus llevó en consideración el instrumental teórico-metodológico proporcionado por la Teoría Semiolinguística del Discurso. Los resultados revelan que, en el género consejo, existe, predominantemente, la identificación del ser mujer-lectora bien como del ser mujer-modelo que funciona como punto de referencia para el primero. Esos seres, conforme el propósito temático del texto, pueden ser calificados como buenas esposas, buenas madres, buenas amas de casa, y/o localizados en situaciones sociales como la del casamiento y la del trabajo.

Palabras-clave: Organización descriptiva. Teoría Semiolinguística. Clarice Lispector.

ROSADO; MELO - Analisando a organização descritiva... 